\title{
Propofol as a Risk Factor for ICU- Acquired Weakness in Septic Patients with Acute Respiratory Failure
}

\author{
Peter A. Abdelmalik, Goran Rakocevic
}

\begin{abstract}
Background: Critical illness polyneuropathy (CIN) and critical illness myopathy (CIM), together "ICU-Acquired weakness (ICUAW)," occur frequently in septic patients. One of the proposed mechanisms for ICUAW includes prolonged inactivation of sodium channels. Propofol, used commonly in patients with acute respiratory failure (ARF), primarily acts via enhancement of GABAergic transmission but may also increase sodium channel inactivation, suggesting a potential interaction. Methods: Electronic medical records and EMG reports of patients with ICUAW and a diagnosis of either sepsis, septicaemia, severe sepsis, or septic shock, concurrent with a diagnosis of acute respiratory failure (ARF), were retrospectively analyzed in a single center university hospital. Results: 74 cases were identified (50.0\% men, age $58 \pm 14$ years), and compared to age- and sex-matched controls. Of these, 51 (69\%) had CIN, 19 (26\%) had CIM, and 4 (5\%) had both. Propofol exposure was significantly higher in patients with ICUAW compared to controls $(63.5 \%$ vs. $33.8 \%, \mathrm{p}<0.001)$. The odds ratio of developing ICUAW with propofol exposure was 3.4 (95\% CI:1.7-6.7, p <0.001). Patients with ICUAW had significantly more days in hospital (59 \pm 44 vs. $30 \pm 23)$ and ICU ( $38 \pm 26$ vs. $17 \pm 13)$, days dependent on mechanical ventilation $(27 \pm 21$ vs. $13 \pm 16)$, and rates of tracheostomy (79.7\% vs. $36.5 \%)$ and gastrostomy $(75.7 \%$ vs. $25.7 \%$ ) (all p < 0.001). They also received a significantly higher number of distinct intravenous antibiotics, cumulative days of antibiotic therapy, and exposure to vasopressors and paralytics. Conclusions: Propofol exposure may increase the risk of ICUAW in septic patients. An interaction through sodium channel inactivation is hypothesized.
\end{abstract}

RÉSUMÉ: Facteur de risque du propofol dans le cas de patients septiques souffrant d'insuffisance respiratoire aiguë et de troubles de la faiblesse musculaire acquis aux soins intensifs. Contexte: La polyneuropathie et la myopathie sont deux troubles qui peuvent apparaître à la suite d'une maladie grave. Dans les deux cas, ils se manifestent par une faiblesse musculaire acquise aux soins intensifs ; ils surviennent aussi fréquemment chez des patients atteints de sepsie. Une des solutions apportées à ce syndrome clinique inclut notamment l'inactivation des canaux sodiques. Couramment utilisé pour soulager des patients souffrant d'insuffisance respiratoire aiguë, le propofol agit principalement en augmentant la transmission GABAergique mais pourrait aussi augmenter l'inactivation des canaux sodiques, ce qui suggère une potentielle interaction. Méthodes: Les dossiers médicaux électroniques et les rapports d'ÉMG de patients atteints de faiblesse musculaire acquise aux soins intensifs, chez qui on avait diagnostiqué une sepsie, une septicémie, une grave sepsie ou un choc septique de même qu'une insuffisance respiratoire aiguë, ont été analysés rétrospectivement au sein d'un centre hospitalier universitaire. Résultats: Au total, 74 cas ont été repérés (50,0\% d'hommes ; âge $58 \pm 14$ ans) et comparés à des témoins du même sexe et du même âge. Sur ces 74 cas, 51 (69\%) étaient atteints de polyneuropathie ; 19 (26\%), de myopathie ; et 4 (5\%), de ces deux troubles. En comparaison avec les témoins, l'exposition au propofol s'est révélée sensiblement plus élevée chez les patients atteints de faiblesse musculaire acquise aux soins intensifs (63,5\% contre $33,8 \% ; \mathrm{p}<0,001)$. Le risque relatif approché d'être aux prises avec un tel syndrome clinique après avoir été soulagé par du propofol était de 3,4 (95\% IC : $1,7-6,7 ; \mathrm{p}<0,001)$. Les patients aux prises avec ce syndrome ont passé beaucoup plus de jours à l'hôpital (59 \pm 44 contre $30 \pm 23)$ et aux soins intensifs $(38 \pm 26$ contre $17 \pm 13)$. Ils ont été aussi dépendants d'un système de ventilation mécanique pendant plus de jours ( $27 \pm 21$ contre $13 \pm 16)$. Leurs taux de trachéostomie $(79,7 \%$ contre $36,5 \%)$ et de gastrostomie $(75,7 \%$ contre $25,7 \%)$, tous les deux p $<0,001$, se sont en outre avérés plus élevés. Finalement, on leur a administré par voie intraveineuse un nombre sensiblement plus élevé d'antibiotiques de divers types. Le cumul des jours comportant un traitement antibiotique et l'exposition à des agents vasopresseurs et paralytiques a également été plus élevé. Conclusions: Il se pourrait que l'exposition au propofol augmente le risque chez des patients atteints de sepsie et souffrant de faiblesse musculaire acquise aux soins intensifs. Selon nous, le tout pourrait s'expliquer par une interaction découlant de l'inactivation des canaux sodiques.

Keywords: Intensive care, Critical care, Paresis, Paralysis

doi:10.1017/cjn.2016.424

Can J Neurol Sci. 2017; 44: 295-303

\section{INTRODUCTION}

Critical illness polyneuropathy (CIN), and critical illness myopathy (CIM), are syndromes of generalized flaccid weakness with diminished reflexes that often develop simultaneously in critically ill patients, for which there are no other obvious neurological causes. ${ }^{1}$ Together known as ICU acquired weakness
From the Department of Anesthesia and Critical Care Medicine, Neurocritical Care Division, The Johns Hopkins University School of Medicine, Baltimore, MD [PAA]; Department of Neurology, Thomas Jefferson University Hospitals, Philadelphia, PA [GR]

Received August 12, 2016. Final Revisions Submitted October 9, 2016. Date of ACCEPTANCE November 13, 2016.

Correspondence to: Peter Abdelmalik, Department of Anesthesia and Critical Care Medicine, Neurocritical Care Division, The Johns Hopkins University School of Medicine, $600 \mathrm{~N}$ Wolfe St., Phipps 455, Baltimore, MD, 21231. Email: pabdelm1@ jhmi.edu 
(ICUAW) ${ }^{2}$ the diagnosis is often postulated when a patient with quadripareisis, or frank quadriplegia, fails to be weaned from mechanical ventilation. Many factors have been implicated in the pathogenesis of ICUAW. A meta-analysis identified the following as possible inciting and contributing factors: hyperglycemia; wide fluctuations of blood glucose in the context of sepsis and multi-organ failure; sepsis; systemic inflammatory response syndrome (SIRS); compromised renal excretion as well as renal replacement therapy; and catecholamine administration. ${ }^{3}$ Others, such as patients' age and gender, severity of illness, and use of certain medications (glucocorticoids, neuromuscular blockers, aminoglycosides, or midazolam) have been largely excluded as precipitating factors. ${ }^{3}$

Several hypotheses exist regarding the pathophysiology of ICUAW, including sodium channel dysfunction. ${ }^{2,4-8}$ Sepsis itself has also been implicated in causing sodium channel dysfunction, in both nerve ${ }^{9}$ and muscle, ${ }^{10}$ by causing a depolarization of resting membrane potential and decreasing the population of available sodium channels in experimental models.

Propofol (2,6-diisopropylphenol) is a common sedative used in critically ill patients. First described for its use as a sedative in the late $1980 \mathrm{~s},{ }^{11,12}$ propofol has become a mainstay sedation drug in the ICU because of its rapid onset (1-2 minutes) and short duration of action (2-8 minutes). ${ }^{13}$ Propofol acts primarily as a direct gammaaminobutyric acid (GABA) agonist at a non-benzodiazepine site. But it also inhibits the N-methyl-D-aspartate (NMDA) receptors and modulates calcium influx through slow calcium-ion channels. ${ }^{14}$ Propofol has also been characterized as acting on sodium channels, both in the central and peripheral nervous systems. It has been shown to inhibit persistent sodium channels in in vitro brain preparations, ${ }^{15}$ and block human skeletal muscle sodium channels in a voltage dependent manner. ${ }^{16}$

Sodium channels are ubiquitous in excitable tissue and are crucial for axon salutatory conduction and muscle cell depolarization. Given the current hypothesis that sepsis causes sodium channel dysfunction and that propofol acts at sodium channels, we further hypothesized that propofol use would be an independent risk factor for the development of ICUAW. To date there have been a no electromyographical/nerve conduction studies (EMG/NCS) linking the use of propofol with ICUAW. However, diaphragmatic force was measured using bilateral anterior magnetic phrenic nerve stimulation (BAMPS) in a group of ten ICU patients, nine of whom were septic, and demonstrated an inverse relationship with diaphragmatic force and cumulative propofol dose, ${ }^{17}$ suggesting a potential interaction.

\section{MethodS}

\section{Subjects}

The database inquires of patients' health information were approved by the Thomas Jefferson University Hospital (TJUH) Institutional Review Board. For this type of study formal consent was not required. Patients with CIN, CIM, or both, were identified retrospectively in two ways. First, a keyword search of the MS Word documents (Microsoft, Redmond, WA) generated by two EMG machines at the Department of Neurology (Nicolet, Natus Neurology, Middleton, WI) using the keywords 'intensive,' 'critical,' 'neurocritical,' 'ICU,' and 'intubated' to identify all EMG studies performed on patients admitted to the medical (including cardiac and bone marrow), neurological, and surgical intensive care units. Patients with documented acute respiratory failure and either sepsis, septicemia, severe sepsis, or septic shock were included for further analysis. Only those patients with the finding of axonal sensorimotor neuropathy or/and myopathy in an ICU setting confirmed by electrophysiological studies were included.

Additionally, the inpatient Electronic Medical Records (EMR) system at TJUH was queried for all patients with a diagnosis of critical illness polyneuropathy (ICD 9: 357.82) or critical illness myopathy (ICD 9: 359.81), who also had concurrent diagnoses of acute respiratory failure (as a medical indication for the use of propofol, ICD 9: 518.81) and one of the following: sepsis (ICD 9: 995.91), septicemia (ICD 9: 038), severe sepsis (ICD 9: 995.92), or septic shock (ICD 9: 785.52).

Once a study cohort was identified, age- and sex-matched controls were identified by preforming another TJUH EMR database query screening all patients with a diagnosis of ARF and either sepsis, severe sepsis, or septic shock.

Exclusion criteria were hospital stay less than 48 hours; outside hospital transfer with outside hospital stay greater than seven days; outside hospital transfer with an existing diagnosis of acute respiratory failure and intubation prior to arrival; a history of new weakness preceding inpatient admission; or a documented history of myasthenia gravis, acute inflammatory demyelinating polyradiculoneuropathy (Guillan-Barre Syndrome, AIDP/GBS), chronic inflammatory demyelinating polyradiculoneuropathy (CIDP), polymyositis, amyotrophic lateral sclerosis (ALS) or other motor neuron disease. Patients with existing tracheostomy or gastrostomy were also excluded. Methods were consistent with guidelines from the STrengthening the Reporting of OBservational studies in Epidemiology (STROBE) for case-control studies.

\section{Patient Data}

Patients' health information review included demographics; hospital and ICU length of stay; duration of mechanical ventilation; rates of tracheostomy and gastrostomy placement; concurrent medical diagnoses (using ICD 9 codes); pertinent medical histories; and the proportion requiring vasopressors, intravenous antibiotics, intravenous steroids, paralytics, titratable propofol or midazolam; and disposition at discharge. Bolus doses of sedation for bedside procedures were not included or reviewed.

The cumulative exposure to each aforementioned medications was tallied as days of exposure. Finally, pertinent laboratory values were reviewed, including blood glucose on admission; hemoglobin $\mathrm{A}_{1} \mathrm{C}$, average serum glucose, protein, albumin, and pre-albumin noted on admission and repeated values; and initial and peak values of creatinine, creatine kinase, and lactate.

\section{Statistics}

Data were analyzed by SPSS version 21 (International Business Machines Corporation, Armonk, NY). Significance was noted at a p-value of $<0.05$.

Nominal data were analyzed by Chi square, or Fisher test where cases tallied less than five. Interval data were subjected to a test of normality using the Shapiro-Wilk test. Age, cumulative aminoglycoside exposure, and average serum glucose were analyzed via independent $\mathrm{T}$ test, and one-way ANOVA. All other values were analyzed using either the Mann Whitney $U$ or the Kruskal Wallis test. 
Bivariate logistic regression was also performed to identify independent risk factors for the diagnosis of ICUAW using a backward conditional approach, starting with known or hypothesized risk factors for ICUAW, including exposure to intravenous antibiotics, vasopressors, paralytics, propofol, midazolam, glucocorticoids; diagnoses of acute hepatitis; septic shock; and protein-calorie malnutrition. These variables were either previously hypothesized as potential inciting factors contributing to the occurence of ICUAW, or, the particular variable had a $\mathrm{p}$ value $<0.2$ when compared between the ICUAW cohort and controls.

\section{RESUlts}

In total, 3716 EMG reports were screened (237 Machine A [Thomas Jefferson Hospital, Gibbon Building] + 472 Machine B [Jefferson Hospital for Neuroscience] + 3007 [Jefferson Hospital for Neuroscience archived hard drive]). Of those, 37 cases were identified, one of which was performed in the outpatient setting. Of the 36 inpatient studies, 11 had a confirmed or suspected diagnosis of AIDP/GBS, three had a diagnosis of myasthenia gravis, one had CIDP, and one had a normal EMG. Of the 20 remaining cases, eight did not have documented sepsis or acute respiratory failure, leaving 12 cases of either CIN or CIM with documented sepsis and acute respiratory failure that underwent inpatient EMG testing.

Query of the TJUH EMR for CIN or CIM yielded 191 potential cases from the years 2000-2014. Of those, 57 did not have a diagnosis of sepsis; nine did not have a diagnosis of acute respiratory failure; 20 cases were repeat diagnoses; 25 were outside hospital transfers with outside hospital stay $>7$ days or intubated prior to arrival; 11 were weak on admission (one with polymyositis, one with motor neuron disease, two with GBS, one with CIDP and six with other diagnoses); and three had an incomplete chart. This left 66 cases, of which four were duplicates of those identified via EMG reports, thus leaving 62, plus the 12 identified via EMG reports, leaving 74 total cases.

Seventy-four age- and sex-matched controls were identified by querying the TJUH EMR for all patients with a diagnosis of ARF and either sepsis, severe sepsis, or septic shock from the years 2010-2014. This generated a list of 2080 patients. Of those, 1238 were screened in order to identify 74 matched controls.

Seventy-four cases of ICUAW were identified with a concurrent diagnosis of sepsis and ARF. Their demographics are depicted in Table 1, and their medical characteristics are depicted in Table 2. Of the 74 cases, $51(68.9 \%)$ had a diagnosis of CIN, 19 (25.7\%) had a diagnosis of CIM, and four $(5.4 \%)$ had a diagnosis of both CIN and CIM. These three groups were statistically similar in the majority of the variables assessed, with the exception of the incidence of acute pancreatitis, the use of IV antibiotics, and serum protein measurements.

The demographics of the 74 patients and 74 controls are compared in Table 3, and their medical characteristics are compared in Table 4. Patients with ICUAW had significantly longer hospital and ICU stays and days of mechanical ventilation, in addition to significantly higher rates of tracheostomy and gastrostomy placements. However, they had a significantly lower in-hospital mortality rate and a higher proportion of discharges to acute inpatient rehabilitation, as compared to controls, with no difference in the incidence of severe sepsis or septic shock, acute hepatitis, or pancreatitis. Additionally, there was no significant difference in the prevalence of cirrhosis or malignancy between the two groups.

ICUAW patients required significantly more vasopressor support, including number of vasopressors used and days of vasopressor exposure, as well as significantly higher intravenous antibiotic quantity and duration, but with no difference specifically in aminoglycoside exposure. ICUAW patients had significantly higher paralytic and propofol exposure, but no difference in the exposure to intravenous steroids (including glucocorticoids), and midazolam.

Of the laboratory values examined, ICUAW patients had significantly lower serum protein levels when initially measured, compared to controls. There were no statistical differences at either baseline or peak between ICUAW patients and controls in admission glucose, hemoglobin A1C, average serum glucose, albumin, prealbumin, creatinine, creatine kinase or lactate.

In order to identify independent predictors of ICUAW in patients with sepsis and ARF, a binary logistic regression was performed using a backwards conditional paradigm starting with the following factors: propofol exposure, midazolam exposure, vasopressor exposure, paralytic exposure, intravenous glucocorticoid exposure, intravenous antibiotic exposure, and diagnoses of acute hepatitis, septic shock, or protein calorie malnutrition. The results are displayed in Table 5. Propofol exposure was an independent predictor of ICUAW with an increased OR of 3.131 (95\% CI: 1.532-6.398). Additionally, exposure to vasopressors was also found to be an independent predictor, with an increased OR of 3.655 (95\%CI: 1.586-8.426). Diagnoses of both septic shock and protein calorie malnutrition neared significance with an OR of approximately 2 , but ultimately had confidence intervals including 1.

\section{Discussion}

Since the initial description of five patients with weakness associated with sepsis and respiratory failure, ${ }^{18}$ sepsis has emerged as an important risk factor for development of ICUAW. 2,4,7,8,19-24 Although several pathophysiological mechanisms have been postulated as underlying causes of ICUAW, sodium channel dysfunction, in association with sepsis, is evolving as a unifying hypothesis for both CIN and CIM. ${ }^{2,4-8}$ Interestingly, the dysfunction of sodium channels has also been implicated in the electrocardiogram-related changes associated in sepsis. ${ }^{25}$

ICUAW can occur as quickly as three days after hospital admission for sepsis, ${ }^{26}$ in keeping with a possible acquired channelopathy. Several reports demonstrate changes in biophysical properties affecting the function of sodium channels in models of sepsis. Lipopolysaccharide has been shown to directly interact with voltage-gated sodium channels and reduce sodium channel availability in transfected cell lines. ${ }^{10}$ In a rat model of chronic sepsis undergoing cecal ligation and perforation, patch clamp techniques demonstrated decreases in both sodium current and conductance, with a hyperpolarizing shift in the inactivation of sodium channels. A cause for this shift may be an upregulation of the $\mathrm{N}_{\mathrm{av}} 1.5$ isoform and a downregulation of the $\mathrm{N}_{\mathrm{av}} 1.4$ due to sepsis. ${ }^{27,28}$

Critically ill patients are routinely provided analgesia and sedation to prevent pain and anxiety, permit invasive procedures, reduce stress and oxygen consumption, and improve synchrony with mechanical ventilation. ${ }^{13}$ Propofol, a commonly used sedative for this indication, has also been studied under patch 
Table 1: Demographics and medical characteristics of patients with critical illness polyneuropathy (CIN), critical illness myopathy (CIM) or the combination of the two (Both)

\begin{tabular}{|c|c|c|c|c|c|}
\hline & & CIN $(n=51)$ & CIM $(n=19)$ & Both $(n=4)$ & $P$ value \\
\hline & Age & $57 \pm 14$ & $58 \pm 18$ & $59 \pm 4$ & 0.926 \\
\hline & Male Gender & $26(51.0 \%)$ & $10(52.6 \%)$ & $1(25.0 \%)$ & 0.585 \\
\hline & BMI & $28.9 \pm 7.1$ & $28.2 \pm 7.1$ & $18.3 \pm 6.6$ & 0.091 \\
\hline & Hospital LOS (Days) & $54 \pm 29$ & $61 \pm 57$ & $104 \pm 104$ & 0.531 \\
\hline & ICU LOS (Days) & $37 \pm 26$ & $33 \pm 18$ & $65 \pm 42$ & 0.226 \\
\hline & Mechanical Ventilation (Days) & $28 \pm 19$ & $26 \pm 17$ & $60 \pm 36$ & 0.127 \\
\hline \multirow[t]{3}{*}{ Location } & MICU & $36(70.6 \%)$ & $9(47.4 \%)$ & $3(75.0 \%)$ & 0.340 \\
\hline & NICU & $7(13.7 \%)$ & $4(21.1 \%)$ & $1(25.0 \%)$ & \\
\hline & SICU & $8(15.7 \%)$ & $6(31.6 \%)$ & 0 & \\
\hline \multirow[t]{7}{*}{ Disposition } & Expired & $6(11.8 \%)$ & $6(31.6 \%)$ & 0 & 0.519 \\
\hline & Home & $2(3.9 \%)$ & 0 & 0 & \\
\hline & Home Health & $2(3.9 \%)$ & 0 & 0 & \\
\hline & Hospice & $2(3.9 \%)$ & $1(5.3 \%)$ & 0 & \\
\hline & Long-term Facility & $16(31.4 \%)$ & $2(10.5 \%)$ & $1(25.0 \%)$ & \\
\hline & Acute Inpatient Rehab & $12(23.5 \%)$ & $7(36.8 \%)$ & $1(25.0 \%)$ & \\
\hline & Skilled Nursing Facility & $11(21.6 \%)$ & $3(15.8 \%)$ & $2(50.0 \%)$ & \\
\hline \multirow[t]{6}{*}{ Medical Diagnoses } & Severe Sepsis & $28(54.9 \%)$ & $12(63.2 \%)$ & $2(50.0 \%)$ & 0.793 \\
\hline & Septic Shock & $26(51.0 \%)$ & $13(68.4 \%)$ & $2(50.0 \%)$ & 0.416 \\
\hline & Aspiration Pneumonia & $17(33.3 \%)$ & $6(31.6 \%)$ & 0 & 0.382 \\
\hline & Acute Pancreatitis & $1(2.0 \%)$ & $3(15.8 \%)$ & $2(50.0 \%)$ & 0.001 \\
\hline & Acute Hepatitis/Liver Necrosis & $9(17.6 \%)$ & $1(5.3 \%)$ & 0 & 0.290 \\
\hline & Protein Calorie Malnutrition & $14(27.5 \%)$ & $7(36.8 \%)$ & $1(25.0 \%)$ & 0.730 \\
\hline \multirow[t]{9}{*}{ Medical Procedures } & Lumbar Puncture & $10(19.6 \%)$ & $3(15.8 \%)$ & $2(50.0 \%)$ & 0.793 \\
\hline & CSF Protein & $224 \pm 331$ & $84 \pm 47$ & $39 \pm 7$ & 0.260 \\
\hline & CSF Glucose & $76 \pm 29$ & $61 \pm 32$ & $80 \pm 61$ & 0.907 \\
\hline & CSF WBC & $262 \pm 546$ & $199 \pm 325$ & $1 \pm 1$ & 0.195 \\
\hline & CSF RBC & $789 \pm 1635$ & $123 \pm 214$ & $56 \pm 3$ & 0.416 \\
\hline & EMG & $11(21.6 \%)$ & 0 & $1(25.0 \%)$ & 0.180 \\
\hline & Biopsy & 0 & $4(21.1 \%)$ & 0 & 0.544 \\
\hline & Tracheostomy & $41(80.4 \%)$ & $14(73.7 \%)$ & $4(100 \%)$ & 0.797 \\
\hline & Gastrostomy & $38(74.5 \%)$ & $15(78.9 \%)$ & $3(75.0 \%)$ & 0.928 \\
\hline \multirow[t]{4}{*}{ Medical History } & Cirrhosis & $6(11.8 \%)$ & 0 & $1(25.0 \%)$ & 0.180 \\
\hline & Malignancy & $12(23.5 \%)$ & $4(21.1 \%)$ & 0 & 0.544 \\
\hline & Cachexia & $4(7.8 \%)$ & $1(5.3 \%)$ & 0 & 0.797 \\
\hline & Diabetes Mellitus & $8(16.0 \%)$ & $3(15.8 \%)$ & $1(25.0 \%)$ & 0.893 \\
\hline
\end{tabular}

clamp conditions. In transfected cell lines, propofol antagonized voltage-gated skeletal muscle, ${ }^{16}$ and $\mathrm{CNS}^{29}$ sodium channels in a concentration-dependent manner, again with a hyperpolarizing shift in the sodium channel inactivation curve. ${ }^{29}$ In a similar fashion, propofol also caused a hyperpolarizing shift in the sodium channel inactivation curve in isolated rat ventricular myocytes in a concentration dependant manner, ${ }^{30}$ which may explain the EKG attenuation noted in septic patients. ${ }^{25}$

Aside from sodium channel dysfunction and electrical inexcitability, other possible mechanisms of ICUAW include muscle protein catabolism, disorganization of muscle ultrastructure with loss of thick myosin filaments, bioenergetics failure, and impaired microcirculation. ${ }^{2,4,6,8}$ Propofol is notorious for causing hemodynamic compromise, which may have a cumulative deleterious effect on the shock of sepsis. We observed that ICUAW patients with exposure to propofol had an increased need for vasopressor support, which is in keeping with this possibility and may extend to the compromise of the microcirculation. Additionally, shock and hypoperfusion are associated with multi organ failure, which has been clearly characterized as a risk factor for ICUAW. . $^{3,31,32}$ 
Table 2: Medical treatments and laboratory results of patients with critical illness polyneuropathy (CIN), critical illness myopathy (CIM) or the combination of the two (Both)

\begin{tabular}{|c|c|c|c|c|c|}
\hline & & $\begin{array}{l}\text { Critical Illness Polyneuropathy } \\
(\mathbf{n}=\mathbf{5 1})\end{array}$ & $\begin{array}{c}\text { Critical Illness Myopathy } \\
(\mathrm{n}=19)\end{array}$ & Both $(n=4)$ & $P$ value \\
\hline \multicolumn{6}{|c|}{ Medical Treatments } \\
\hline \multirow[t]{3}{*}{ Cardiovascular } & Required Vasopressor Support & $38(74.5 \%)$ & $16(84.2 \%)$ & $4(100 \%)$ & 0.669 \\
\hline & Average Number of Vasopressors & $1 \pm 1$ & $2 \pm 2$ & $2 \pm 1$ & 0.186 \\
\hline & Cumulative Vasopressor Exposure (Days) & $6 \pm 8$ & $11 \pm 13$ & $8 \pm 11$ & 0.451 \\
\hline \multicolumn{6}{|c|}{ Infectious Disease } \\
\hline & Required IV Antibiotics & $51(100 \%)$ & $19(100 \%)$ & $3(75 \%)$ & $<0.001$ \\
\hline & Average Number of Antibiotics & $6 \pm 2$ & $6 \pm 2$ & $8 \pm 3$ & 0.457 \\
\hline & Cumulative Antibiotic Exposure (Days) & $49 \pm 30$ & $62 \pm 48$ & $80 \pm 54$ & 0.289 \\
\hline & Received IV Aminoglycosides & $25(49.0 \%)$ & $10(52.6 \%)$ & $2(50.0 \%)$ & 0.965 \\
\hline & Cumulative Aminoglycoside Exposure (Days) & $2.1 \pm 3.6$ & $2.8 \pm 4.7$ & $4.8 \pm 5.8$ & 0.384 \\
\hline \multicolumn{6}{|l|}{ Endocrine } \\
\hline & Required IV steroids & $33(64.7 \%)$ & $9(47.4 \%)$ & $2(50.0 \%)$ & 0.390 \\
\hline & Required IV Glucocorticoids & $24(47.1 \%)$ & $6(31.6 \%)$ & $1(25.0 \%)$ & 0.522 \\
\hline & Cumulative Glucocorticoid Exposure (Days) & $5 \pm 9$ & $5 \pm 9$ & $7 \pm 14$ & 0.567 \\
\hline & Cumulative Mineralocorticoid Exposure (Days) & $4 \pm 8$ & $3 \pm 6$ & $3 \pm 7$ & 0.917 \\
\hline \multicolumn{6}{|l|}{ Sedation } \\
\hline & Required IV Paralytic & $19(37.3 \%)$ & $7(36.8 \%)$ & $1(25.0 \%)$ & 0.886 \\
\hline & Cumulative IV Paralytic Exposure (Days) & $1 \pm 2$ & $1 \pm 2$ & $2 \pm 3$ & 0.916 \\
\hline & Received Propofol & $33(64.7 \%)$ & $11(57.9 \%)$ & $3(75.0 \%)$ & 0.772 \\
\hline & Cumulative Propofol Exposure (Days) & $3 \pm 4$ & $3 \pm 4$ & $4 \pm 6$ & 0.919 \\
\hline & Received Midazolam & $33(64.7 \%)$ & $12(63.2 \%)$ & $2(50.0 \%)$ & 0.926 \\
\hline & Cumulative Midazlam Exposure (Days) & $6 \pm 8$ & $4 \pm 5$ & $7 \pm 11$ & 0.540 \\
\hline \multicolumn{6}{|c|}{ Laboratory Results } \\
\hline & Admission Glucose (mg/dL) & $144 \pm 59$ & $141 \pm 60$ & $104 \pm 15$ & 0.370 \\
\hline & Hemoglobin A1C (\%) & $7 \pm 1$ & $6 \pm 1$ & $6 \pm 0$ & 0.538 \\
\hline & Average Serum Glucose (mg/dL) & $133.8 \pm 27.0$ & $140.7 \pm 23.6$ & $131.1 \pm 32.9$ & 0.594 \\
\hline & Protein $(\mathrm{g} / \mathrm{dL})$ & $5.6 \pm 1.1$ & $5.1 \pm 1.1$ & $4.1 \pm 1.2$ & 0.033 \\
\hline & Albumin $(\mathrm{g} / \mathrm{dL})$ & $2.8 \pm 0.7$ & $3.1 \pm 1.1$ & $2.1 \pm 1.0$ & 0.419 \\
\hline & Prealbumin (mg/dL) & $12 \pm 8$ & $10 \pm 5$ & $10 \pm 4$ & 0.697 \\
\hline & Creatinine (mg/dL) initial & $1.7 \pm 2.1$ & $2.2 \pm 1.8$ & $2.4 \pm 2.3$ & 0.546 \\
\hline & Creatinine $(\mathrm{mg} / \mathrm{dL})$ peak & $3.1 \pm 2.5$ & $6.4 \pm 13.0$ & $3.1 \pm 2.6$ & 0.710 \\
\hline & Creatine Kinase (IU/L) initial & $451 \pm 977$ & $803 \pm 1495$ & $494 \pm 777$ & 0.986 \\
\hline & Creatine Kinase (IU/L) peak & $1357 \pm 3114$ & $1153 \pm 2317$ & $1305 \pm 1236$ & 0.716 \\
\hline & Lactate $(\mathrm{mmol} / \mathrm{L})$ initial & $15 \pm 29$ & $14 \pm 25$ & $5 \pm 4$ & 0.228 \\
\hline & Lactate $(\mathrm{mmol} / \mathrm{L})$ peak & $23 \pm 34$ & $29 \pm 45$ & $5 \pm 3$ & 0.613 \\
\hline
\end{tabular}

Aside from its effect at sodium channels, propofol itself may exacerbate ICUAW by other putative mechanisms. For example, anesthesia with profofol has been associated with rhabdomyolysis secondary to skeletal muscle breakdown, described in two patients receiving high rates of propofol infusion, with markedly elevated creatine kinase and histopathology demonstrating necrosis with swelling, loss of striation, and vacuole formation. ${ }^{33}$ Propofol infusion syndrome is a rare but potentially lethal side effect of propofol, presenting with rhabdomyolysis in addition to metabolic acidosis, hyperkalaemia, hepatomegaly, renal failure, hyperlipidaemia, arrhythmia, and rapidly progressive cardiac failure. ${ }^{34}$ In vitro studies in cortical mixed neuronal/glial cultures have shown that relevant concentrations of propofol are involved in altered retrograde intracellular transport and neurite retraction via actin reorganization. ${ }^{35}$ Similar observations have not been reported in muscle tissue. Lastly, when exposed to supratherapeutic concentrations of propofol, mitochondria isolated from neurons of embryonic stem cells demonstrate increased fission 
Table 3: Demographics of patients with ICU-acquired weakness (ICUAW) versus controls

\begin{tabular}{|c|c|c|c|c|}
\hline & & ICUAW $(n=74)$ & Control $(n=74)$ & $P$ value \\
\hline & Age & $58 \pm 14$ & $58 \pm 14$ & 1.000 \\
\hline & Male Gender & $37(50 \%)$ & $37(50 \%)$ & 1.000 \\
\hline & BMI & $28.2 \pm 9.3$ & $26.3 \pm 5.8$ & 0.583 \\
\hline & Hospital LOS (Days) & $59 \pm 44$ & $30 \pm 23$ & $<0.001$ \\
\hline & ICU LOS (Days) & $38 \pm 26$ & $17 \pm 13$ & $<0.001$ \\
\hline & Mechanical Ventilation (Days) & $27 \pm 21$ & $13 \pm 16$ & $<0.001$ \\
\hline \multirow[t]{3}{*}{ Location } & $\mathrm{MICU}$ & $48(64.9 \%)$ & $48(64.9 \%)$ & 0.962 \\
\hline & NICU & $12(16.2 \%)$ & $11(14.9 \%)$ & \\
\hline & SICU & $14(18.9 \%)$ & $15(20.3 \%)$ & \\
\hline \multirow[t]{10}{*}{ Disposition } & Against Medical Advice & 0 & $1(1.4 \%)$ & 0.001 \\
\hline & Another Hospital & 0 & $1(1.4 \%)$ & \\
\hline & Expired & $12(16.2 \%)$ & $33(44.6 \%)$ & \\
\hline & Home & $2(2.7 \%)$ & $2(2.7 \%)$ & \\
\hline & Home Health & $2(2.7 \%)$ & $6(8.1 \%)$ & \\
\hline & Hospice & $3(4.1 \%)$ & $1(1.4 \%)$ & \\
\hline & Long Term Facility & $19(25.7 \%)$ & $8(10.8 \%)$ & \\
\hline & Inpatient Psychiatry & 0 & $1(1.4 \%)$ & \\
\hline & Acute Inpatient Rehab & $20(27.0 \%)$ & $6(8.1 \%)$ & \\
\hline & Skilled Nursing Facility & $16(21.6 \%)$ & $15(20.3 \%)$ & \\
\hline \multirow[t]{6}{*}{ Medical Diagnoses } & Severe Sepsis & $42(56.8 \%)$ & $44(59.5 \%)$ & 0.739 \\
\hline & Septic Shock & $41(55.4 \%)$ & $48(64.9 \%)$ & 0.240 \\
\hline & Aspiration Pneumonia & $23(31.1 \%)$ & $19(25.7 \%)$ & 0.466 \\
\hline & Acute Pancreatitis & $6(8.1 \%)$ & $4(5.4 \%)$ & 0.512 \\
\hline & Acute Hepatitis/Liver Necrosis & $10(13.5 \%)$ & $16(21.6 \%)$ & 0.195 \\
\hline & Protein Calorie Malnutrition & $22(29.7 \%)$ & $12(16.2 \%)$ & 0.051 \\
\hline \multirow[t]{3}{*}{ Medical Procedures } & Lumbar Puncture & $7(9.5 \%)$ & $8(10.8 \%)$ & 0.622 \\
\hline & Tracheostomy & $59(79.7 \%)$ & $27(36.5 \%)$ & $<0.001$ \\
\hline & Gastrostomy & $56(75.7 \%)$ & $19(25.7 \%)$ & $<0.001$ \\
\hline \multirow[t]{4}{*}{ Medical History } & Cirrhosis & $7(9.5 \%)$ & $7(9.5 \%)$ & 1.000 \\
\hline & Malignancy & $16(21.6 \%)$ & $24(32.4 \%)$ & 0.139 \\
\hline & Cachexia & $5(6.8 \%)$ & $2(2.7 \%)$ & 0.245 \\
\hline & Diabetes Mellitus & $12(16.2 \%)$ & $12(16.2 \%)$ & 0.971 \\
\hline
\end{tabular}

and increased expression of mitochondrial permeability transition pore, inducing neurotoxicity. ${ }^{36}$

The incidence of ICUAW is exceedingly high, occurring in approximately 50-70\% of Intensive Care Unit (ICU) patients with diagnoses of sepsis or multi-organ failure. ${ }^{3,4}$ In patients with a diagnosis of septic shock the incidence can rise to $70-80 \%{ }^{20,23,24}$ However, our query of the EMR yielded a total of only 191 cases of appropriately coded CIN or CIM in the span of 14 years, suggesting ICUAW is grossly underdiagnosed. Additionally, a preponderance of ICUAW cases reported here were CIN, which contradicts previous reports suggesting $\mathrm{CIM}^{19,37}$ or the combination $^{26}$ occur more frequently. Both the underdiagnosis and possible misdiagnosis of patients with ICUAW may be in part due to the lack of proven effective interventions and the difficulty in making the diagnosis on the basis of the clinical exam alone.
There is then the added complexity in obtaining supporting electrodiagnostics in the ICU in routine clinical practice, due to the ongoing nursing care of acutely ill patients, the presence of electrical artefacts and other limiting factors for quality studies such as patient's sedation and edema, and the lack of clinically proven effective therapies. $^{2}$

In our cohort of ICUAW patients only $16 \%$ of diagnoses (12 patients) were made with EMG/NCS and only two patients underwent biopsy; these methods are recognized as the gold standard for diagnosis. Instead, the majority of CIN or CIM diagnoses were made on clinical grounds alone, without the use of electrodiagnostics or pathology. In a prospective study of mechanically ventilated ICU patients, using a clinical exam with low threshold criteria for the diagnosis of CIN (e.g. the presence of paresis or areflexia) was only $60 \%$ sensitive compared to 
Table 4: Medical treatments and laboratory results of patients with ICU-acquired weakness (ICUAW) versus controls

\begin{tabular}{|c|c|c|c|c|}
\hline & & ICUAW $(n=74)$ & Controls $(n=74)$ & $P$ value \\
\hline \multicolumn{5}{|l|}{ Medical Treatments } \\
\hline \multirow[t]{3}{*}{ Cardiovascular } & Required Vasopressor Support & $58(78.4 \%)$ & $43(58.1 \%)$ & 0.005 \\
\hline & Average Number of Vasopressors & $2 \pm 1$ & $1 \pm 1$ & 0.024 \\
\hline & Cumulative Vasopressor Exposure (Days) & $7 \pm 10$ & $5 \pm 11$ & 0.013 \\
\hline \multirow[t]{5}{*}{ Infectious Disease } & Required IV Antibiotics & $73(98.6 \%)$ & $74(100 \%)$ & 0.316 \\
\hline & Average Number of Antibiotics & $6 \pm 2$ & $5 \pm 1$ & $<0.001$ \\
\hline & Cumulative Antibiotic Exposure (Days) & $54 \pm 37$ & $36 \pm 29$ & $<0.001$ \\
\hline & Received IV Aminoglycosides & $37(50.0 \%)$ & $28(37.8 \%)$ & 0.136 \\
\hline & Cumulative Aminoglycoside Exposure (Days) & $2.4 \pm 4.1$ & $1.6 \pm 4.2$ & 0.218 \\
\hline \multirow[t]{4}{*}{ Endocrine } & Required IV steroids & $44(59.5 \%)$ & $47(63.5 \%)$ & 0.612 \\
\hline & Required IV Glucocorticoids & $31(41.9 \%)$ & $31(41.9 \%)$ & 1.000 \\
\hline & Cumulative Glucocorticoid Exposure (Days) & $5 \pm 9$ & $2 \pm 4$ & 0.436 \\
\hline & Cumulative Mineralocorticoid Exposure (Days) & $4 \pm 8$ & $4 \pm 9$ & 0.962 \\
\hline \multirow[t]{6}{*}{ Sedation } & Required IV Paralytic & $27(36.5 \%)$ & $16(21.6 \%)$ & 0.046 \\
\hline & Cumulative IV Paralytic Exposure (Days) & $1 \pm 2$ & $0 \pm 1$ & 0.006 \\
\hline & Received Propofol & $47(63.5 \%)$ & $25(33.8 \%)$ & $<0.001$ \\
\hline & Cumulative Propofol Exposure (Days) & $3 \pm 4$ & $1 \pm 2$ & 0.001 \\
\hline & Received Midazolam & $47(63.5 \%)$ & $44(59.5 \%)$ & 0.612 \\
\hline & Cumulative Midazlam Exposure (Days) & $6 \pm 7$ & $5 \pm 6$ & 0.627 \\
\hline \multirow[t]{12}{*}{ Laboratory Results } & Admission Glucose (mg/dL) & $141 \pm 58$ & $143 \pm 84$ & 0.291 \\
\hline & Hemoglobin A1C (\%) & $6 \pm 1$ & $7 \pm 3$ & 0.456 \\
\hline & Average Serum Glucose (mg/dL) & $135.4 \pm 26.3$ & $133.2 \pm 34.9$ & 0.655 \\
\hline & Protein $(\mathrm{g} / \mathrm{dL})$ & $5.4 \pm 1.1$ & $6.0 \pm 1.7$ & 0.027 \\
\hline & Albumin $(\mathrm{g} / \mathrm{dL})$ & $2.8 \pm 0.8$ & $3.0 \pm 0.8$ & 0.289 \\
\hline & Prealbumin $(\mathrm{mg} / \mathrm{dL})$ & $11.6 \pm 7.5$ & $9.5 \pm 6.0$ & 0.126 \\
\hline & Creatinine $(\mathrm{mg} / \mathrm{dL})$ initial & $1.9 \pm 2.0$ & $1.9 \pm 2.0$ & 0.642 \\
\hline & Creatinine $(\mathrm{mg} / \mathrm{dL})$ peak & $4.0 \pm 6.9$ & $3.2 \pm 2.2$ & 0.975 \\
\hline & Creatine Kinase (IU/L) initial & $543 \pm 1113$ & $319 \pm 557$ & 0.809 \\
\hline & Creatine Kinase (IU/L) peak & $1302 \pm 2828$ & $913 \pm 1733$ & 0.937 \\
\hline & Lactate $(\mathrm{mmol} / \mathrm{L})$ initial & $14.4 \pm 27.2$ & $23.5 \pm 41.4$ & 0.091 \\
\hline & Lactate $(\mathrm{mmol} / \mathrm{L})$ peak & $23.6 \pm 36.5$ & $39.6 \pm 56.2$ & 0.099 \\
\hline
\end{tabular}

EMG diagnosis ${ }^{38}$ suggesting many cases remain undiagnosed, as previously discussed. Direct muscle stimulation has been shown to differentiate CIN from CIM in comatose or encephalopathic critically ill patients. ${ }^{39}$ The Medical Research Council (MRC) advocates using the MRC sum score as an initial diagnostic measure of muscle force in conscious patients who are suspected of having critical illness polyneuropathy or myopathy, where ICAW are arbitrarily diagnosed if the MRC sum score is

Table 5: Logistic regression using a backwards conditional model to identify independent predictors of ICUAW. Initial starting variables included exposure to intravenous antibiotics, vasopressors, paralytics, propofol, midazolam, glucocorticoids, and diagnoses of acute hepatitis, septic shock and protein-calorie malnutrition

\begin{tabular}{l|c|c|c|c}
\hline & p Value & Odds Ratio & Upper 95\% CI & Lower 95\% CI \\
\hline Propofol & 0.002 & 3.131 & 1.532 & 6.398 \\
\hline Vasopressor & 0.002 & 3.655 & 1.586 & 8.426 \\
\hline Septic Shock & 0.068 & 2.079 & 0.949 & 4.545 \\
\hline Protein Calorie Malnutrition & 0.076 & 2.179 & 0.923 & 5.146 \\
\hline
\end{tabular}


less than $48 .^{32,40}$ However, our patients were intubated and sedated with several agents, including propofol, midazolam, and fentanyl, making routine use of this score in this patient population difficult. Future potential diagnostic modalities may include ultrasound, ${ }^{41}$ or peroneal nerve electrophysiological test (PENT), a simplified electrophysiological assessment of a single nerve which demonstrated a sensitivity of $100 \%$ and a specificity of $85.2 \%$ compared to comprehensive EMG/NCS in critically ill patients. ${ }^{42}$

Another limitation of this study is the significantly higher mortality rate in the control group, at $44.6 \%$ compared to the ICUAW group at $16.2 \%$. Recently published mortality rates for sepsis are approximately $30 \%,{ }^{43}$ whereas severe sepsis and septic shock may reach as high as $50 \% .^{44-48}$ The diagnosis of CIN or CIM in the setting of sepsis or septic shock may have introduced a selection bias for survivors of the acute medical illness (e.g. sepsis and multi-organ failure), which translated into decreased mortality, but also significantly higher hospital and ICU length of stay, days of mechanical ventilation, rates of tracheostomy and gastrostomy placements, and patients who were discharged to acute rehabilitation or long term care facilities (Table 2). This is in contrast to previous reports suggesting that ICUAW was a risk factor for increased in-hospital mortality. ${ }^{19,24,26}$ Furthermore, it is possible that the control group of septic patients with ARF may have also had undiagnosed ICUAW.

There was no statistical difference between ICUAW patients and controls with respect to the proportion of patients with the diagnosis of septic shock; age, initial, or peak serum lactate; or creatinine or glucose control, suggesting a similar level of medical acuity between the two groups. However, the use ICU scoring systems such as the APACHE II or III, SAPS II, and SOFA were not documented during the patients' hospitalization. These classifications would have allowed for the expected mortality of the respective cohorts to be calculated, and may have helped clarify the large differences in observed mortality between the two groups.

We did, however, note that patients with ICUAW required significantly more intravenous antibiotics and vasopressors which, in light of the difference in mortality, may have been an artefact of exposure bias and longer hospitalizations, and thus must be interpreted cautiously.

Lastly, propofol exposure was assumed to be a consequence of $\mathrm{ARF}$ and mechanical ventilation, which were inclusion criteria for the study. In some cases, however, propofol exposure may have been the result of isolated bolus doses given for bedside procedures and not as a continuous infusion for sedation with mechanical ventilation. Additionally, the diagnosis of ICUAW may have preceded the propofol exposure in some cases. An examination of the duration of propofol exposure, measured by days of exposure, attempted to address these potential confounders. However, we estimated propofol exposure based on days of exposure, which is a crude estimate of exposure; actual individual doses may have varied considerably from patient to patient. Accurate hourly infusion rates of propofol were not charted, thus restricting the ability to explore the presence of a potential dose response relationship between propofol and ICUAW in patients with sepsis and ARF.

Both sepsis and propofol act to increase the inactivation of sodium channels. The data presented here, although significantly limited by the difficulty in making the diagnosis of ICUAW on clinical grounds alone, suggest that propofol exposure may be an independent risk factor in the development of ICUAW in patients with sepsis. On the other hand, the onset of ICUAW may prolong the need for mechanical ventilation in patients with ARF, which would in turn require longer exposure to propofol and other sedatives. Further studies, both basic science and clinical, with supporting EMG/NCS and biopsy, are warranted to confirm the supposition that propofol may act synergistically at sodium channels, along with sepsis, causing sodium channel dysfunction, leading to the impairment of excitable membranes.

\section{ACKOWLedGements}

We would like to thank Ms. Micky Triocci for her help querying the EMR, and Ms. Karlene Copeland for her help in querying the EMG reports.

All procedures performed in studies involving human participants were in accordance with the ethical standards of the institutional and/ or national research committee and with the 1964 Helsinki declaration and its later amendments or comparable ethical standards.

\section{Disclosures}

Peter Abdelmalik and Goran Rakocevic have no financial or other interests to disclose.

\section{Statement of Authorship}

Peter Abdelmalik and Goran Rakocevic both oversaw the experimental design, data retrieval, data analysis and manuscript preparation.

\section{REFERENCES}

1. Fan E, Cheek F, Chlan L, Gosselink R, Hart N, Herridge MS, et al. An Official American Thoracic Society Clinical Practice Guideline: The Diagnosis of Intensive Care Unit-acquired Weakness in Adults. Am J Respir Crit Care Med [Internet]. 2014;190(12):1437-46.

2. Schweickert WD, Hall J. ICU-acquired weakness. Chest. 2007;131 (5):1541-9.

3. Stevens RD, Dowdy DW, Michaels RK, Mendez-Tellez P a., Pronovost PJ, Needham DM. Neuromuscular dysfunction acquired in critical illness: A systematic review. Intensive Care Med. 2007;33(11):1876-91.

4. Kress JP, Hall JB. ICU-acquired weakness and recovery from critical illness. N Engl J Med [Internet]. 2014;370:1626-35.

5. Z'Graggen WJ, Lin CSY, Howard RS, Beale RJ, Bostock H. Nerve excitability changes in critical illness polyneuropathy. Brain. 2006;129(9):2461-70.

6. Bloch S, Polkey MI, Griffiths M, Kemp P. Molecular mechanisms of intensive care unit-acquired weakness. Eur Respir J. 2012; 39(4):1000-11.

7. Lacomis D. Electrophysiology of neuromuscular disorders in critical illness. Muscle Nerve [Internet]. 2013, Mar [cited 2014 May 1] 47(3):452-63.

8. Latronico N, Bolton CF. Critical illness polyneuropathy and myopathy: A major cause of muscle weakness and paralysis. Lancet Neurol [Internet] Elsevier Ltd 2011;10(10):931-41.

9. Novak KR, Nardelli P, Cope TC, Filatov G, Glass JD, Khan J, et al. Inactivation of sodium channels underlies reversible neuropathy during critical illness in rats. J Clin Invest. 2009;119(5):1150-8.

10. Haeseler G, Foadi N, Wiegand E, Ahrens J, Krampfl K, Dengler R, et al. Endotoxin reduces availability of voltage-gated human skeletal muscle sodium channels at depolarized membrane potentials. Crit Care Med. 2008;36(4):1239-47.

11. Grounds RM, Lalor JM, Lumley J, Royston D, Morgan M. Propofol infusion for sedation in the intensive care unit: preliminary report. Br Med J (Clin Res Ed). 1987;294(6569):397-400.

12. Newman LH, McDonald JC, Wallace PG, Ledingham IM. Propofol infusion for sedation in intensive care. Anaesthesia. 1987; 42(9):929-37. 
13. Hughes CG, McGrane S, Pandharipande PP. Sedation in the intensive care setting. Clin Pharmacol Adv Appl. 2012;4(1):53-63.

14. Kotani Y, Shimazawa M, Yoshimura S, Iwama T, Hara H. The experimental and clinical pharmacology of propofol, an anesthetic agent with neuroprotective properties. CNS Neurosci Ther [Internet]. 2008, Jan [cited 2014 May 14] 14(2):95-106.

15. Martella G, De Persis C, Bonsi P, Natoli S, Cuomo D, Bernardi G, et al. Inhibition of persistent sodium current fraction and voltagegated L-type calcium current by propofol in cortical neurons: implications for its antiepileptic activity. Epilepsia [Internet]. 2005, May 46(5):624-35.

16. Haeseler G, Störmer M, Bufler J, Dengler R, Hecker H, Piepenbrock $\mathrm{S}$, et al. Propofol blocks human skeletal muscle sodium channels in a voltage-dependent manner. Anesth Analg [Internet]. 2001, May 92(5):1192-8.

17. Hermans G, De Jonghe B, Bruyninckx F, Van Den Berghe G. Interventions for preventing critical illness polyneuropathy and critical illness myopathy. Cochrane Database Syst Rev. 2014:(1):1-68.

18. Bolton CF, Gilbert JJ, Hahn a F, Sibbald WJ. Polyneuropathy in critically ill patients. J Neurol Neurosurg Psychiatry. 1984; 47(11):1223-31.

19. Latronico N, Fenzi F, Recupero D, Guarneri B, Tomelleri G, Tonin P, et al. Critical illness myopathy and polyneuropathy.pdf. Lancet. 1996;347:1579-82.

20. Witt NJ, Zochodne DW, Bolton CF, Grand'Maison F, Wells G, Young GB, et al. Peripheral nerve function in sepsis and multiple organ failure. Chest J. 1991;99(1):176-84.

21. Zochodne DW, Bolton CF, Wells G a, Gilbert JJ, Hahn a F, Brown JD, et al. Critical illness polyneuropathy. A complication of sepsis and multiple organ failure. Brain. 1987;110 ( Pt 4): 819-41.

22. Bolton CF, Laverty D a, Brown JD, Witt NJ, Hahn a F, Sibbald WJ. Critically ill polyneuropathy: electrophysiological studies and differentiation from Guillain-Barré syndrome. J Neurol Neurosurg Psychiatry. 1986;49(5):563-73.

23. Berek K, Margreiter J, Willeit J, Berek a, Schmutzhard E, Mutz NJ. Polyneuropathies in critically ill patients: a prospective evaluation. Intensive Care Med. 1996;22(9):849-55.

24. Garnacho-Montero J, Madrazo-Osuna J, García-Garmendia J, Ortiz-Leyba C, Jiménez-Jiménez F, Barrero-Almodóvar a., et al. Critical illness polyneuropathy: Risk factors and clinical consequences. A cohort study in septic patients. Intensive Care Med. 2001;27(8):1288-96.

25. Rich MM, McGarvey ML, Teener JW, Frame LH. ECG changes during septic shock. Cardiology. 2002;97(4):187-96.

26. Khan J, Harrison TB, Rich MM, Moss M. Early development of critical illness myopathy and neuropathy in patients with severe sepsis. Neurology. 2006;67(8):1421-5.

27. Teener JW, Rich MM. Dysregulation of sodium channel gating in critical illness myopathy. J Muscle Res Cell Motil. 2006; 27(5-7):291-6.

28. Friedrich O, Hund E, Weber C, Hacke W, Fink RH a. Critical illness myopathy serum fractions affect membrane excitability and intracellular calcium release in mammalian skeletal muscle. J Neurol. 2004;251(1):53-65.

29. Rehberg B, Duch DS. Suppression of central nervous system sodium channels by propofol. Anesthesiology. 1999;91(2):512-20.

30. Saint D. The effects of propofol on macroscopic and single channel sodium currents in rat ventricular myocytes. Br J Pharmacol. 1998;124(4):655-62.

31. de Letter M, Schmitz PI, Visser LH, Verheul FA, Schellens RL, Op de Coul DA, et al. Risk factors for the development of polyneuropathy and myopathy in critically ill patients. Crit Care Med. 2001;29(12):2281-6.
32. De Jonghe B, Sharshar T, Lefaucheur JP, Authier FJ, Durand-Zaleski I, Boussarsar M, et al. Paresis Acquired in the Intensive Care Unit. JAMA. 2002;288(22):2859-67.

33. Stelow EB, Johari VP, Smith SA, Crosson JT, Apple FS. Propofol-associated rhabdomyolysis with cardiac involvement in adults: Chemical and anatomic findings. Clin Chem. 2000; 46(4):577-81.

34. Krajčová A, Waldauf $P$, Anděl M, Duška F, Krajcova A. Propofol infusion syndrome : a structured review of experimental studies and 153 published case reports. Crit Care [Internet]. 2015;19(1): $1-9$.

35. Turina D, Bjornstrom K, Sundqvist T, Eintrei C, Sciences H, Medicine E. Propofol Alters Vesicular Transport in Rat Cortical Neuronal Cultures. J Physiol Pharmacol. 2011;61(1):119-24.

36. Twaroski DM, Yan Y, Zaja I, Clark E, Bosnjak ZJ, Bai X. Altered Mitochondrial Dynamics Contributes to Propofol-induced Cell Death in Human Stem Cell-derived Neurons. Anesthesiology [Internet]. 2015;123(5):1067-83.

37. Koch S, Spuler S, Deja M, Bierbrauer J, Dimroth A, Behse F, et al. Critical illness myopathy is frequent: accompanying neuropathy protracts ICU discharge. J Neurol Neurosurg Psychiatry. 2011; 82(3):287-93

38. Leijten FS, Poortvliet DC, de Weerd a W. The neurological examination in the assessment of polyneuropathy in mechanically ventilated patients. Eur J Neurol [Internet]. 1997;4(2):124-9.

39. Rich MM, Bird SJ, Raps EC, McCluskey LF, Teener JW. Direct muscle stimulation in acute quadriplegic myopathy. Muscle and Nerve. 1997;20(6):665-73.

40. Zhou C, Wu L, Ni F, Ji W, Wu J, Zhang H. Critical illness polyneuropathy and myopathy: A systematic review. Neural Regen Res. 2014;9(1):101-10.

41. Puthucheary Z a, Rawal J, McPhail M, Connolly B, Ratnayake G, Chan P, et al. Acute skeletal muscle wasting in critical illness. JAMA [Internet]. 2013;310(15):1591-600.

42. Latronico N, Nattino G, Guarneri B, Fagoni N, Amantini A, Bertolini G. Validation of the peroneal nerve test to diagnose critical illness polyneuropathy and myopathy in the intensive care unit: the multicentre Italian CRIMYNE-2 diagnostic accuracy study. F1000Research [Internet]. 2014:1-11; Available from: http:// f1000research.com/articles/3-127/v1.

43. Mouncey PR, Osborn TM, Power GS, Harrison D a, Sadique MZ, Grieve RD, et al. Trial of Early, Goal-Directed Resuscitation for Septic Shock for the ProMISe Trial Investigators. N Engl J Med. 2015;372(14):1301-11.

44. Carson SS, Kress JP, Rodgers JE, Vinayak A, Campbell-Bright S, Levitt J, et al. A randomized trial of intermittent lorazepam versus propofol with daily interruption in mechanically ventilated patients. Crit Care Med. 2006;34(5):1326-32.

45. Angus DC, Linde-Zwirble WT, Lidicker J, Clermont G, Carcillo J, Pinsky MR. Epidemiology of severe sepsis in the United States: analysis of incidence, outcome, and associated costs of care. Crit Care Med. 2001;29(7):1303-10.

46. Rusconi AM, Bossi I, Lampard JG, Szava-Kovats M, Bellone A, Lang E. Early goal-directed therapy vs usual care in the treatment of severe sepsis and septic shock: a systematic review and metaanalysis. Intern Emerg Med [Internet] Springer Milan 2015, Available from: http://link.springer.com/10.1007/s11739-0151248 -y.

47. Annane D, Bellissant E, Cavaillon J-M. Septic shock. Lancet. 2005;365(9453):63-78.

48. Annane D, Aegerter P, Jars-Guincestre MC, Guidet B. Current epidemiology of septic shock: The CUB-Rea network. Am J Respir Crit Care Med. 2003;168(2):165-72. 